\title{
AGREEMENT ON THE ADMISSION OF GUILT (PLEA BARGAIN) IN CRIMINAL PROCEEDINGS (COMPARATIVE LEGAL ANALYSIS)
}

\author{
I. I. Belozerova ${ }^{1}$, D. Y. Moskovskikh ${ }^{2}$ \\ ${ }^{1} \mathrm{PhD}$ in Law, Associate Professor at the Chair of Criminal Law, Criminal Procedure and \\ Criminalistics of the Law Institute of the Peoples' Friendship University of Russia (RUDN \\ University); Professor at the Chair of Procedural Law of the Russian Foreign Trade Academy \\ (VAVT) beloz-irina@mail.ru \\ ${ }^{2}$ Post-graduate student of the Department of Criminal Law, Criminal Procedure and Criminalistics, \\ RUDN dinat81@mail.ru
}

\begin{abstract}
The practice of agreements (plea bargains) in conflict resolution has always existed. However, in different countries, the legislator gave them a legal character at certain stages of history, depending on the workload of the courts or the need to simplify the system. Anyway, in the criminal process, this is a means of mitigating punishment. At the same time, there are still disputes about the fairness of this already integral part of the legal system. The topic of the article brings to the fore the coercive nature, abuse of authority, and other possible shortcomings. It should be noted that the admission of guilt and the achievement of a plea bargain does not mean connivance on the part of the authorities in terms of a qualitaty investigation of the circumstances of the case and establishing the facts, so that the guilty person does not escape attention and the innocent person does not suffer.

Based on the analysis of the current legislation, the relationship of the term "agreement" of the civil law branch and as used in the criminal process of the Russian Federation is clarified. It cannot be denied that in most cases criminal law disputes are resolved using a sanctions approach. At the same time, given that there is a tendency to humanize criminal procedural activities aimed not only at exposing the perpetrators and bringing them to justice for the illegal act committed, it is reasonable and natural to reach an agreement between the parties with different interests. The compromise of this legal phenomenon is regulated by the provisions of the legislation. Meanwhile, a number of features have unstable characteristics, which leads to the adoption of unfair decisions. The authors pay special attention to the attitude to plea deals in the legislation of different countries. In addition, the role of the admission of guilt and confessions in the procedural activity and the result of the consideration of a criminal case is investigated. At the same time, it is concluded that the specified legal institution is not the main criterion for distinguishing procedures, it is a set of actions of the person involved, aimed both at a quick resolution of the case and at minimizing possible punishment. It is also important that there is necessarily a voluntary nature in reaching agreements. The conclusion considers the possibility and necessity of introducing a new participant in criminal procedural relations - a mediator, as well as a new stage of the process - mediation.
\end{abstract}

Keywords: plea bargain, agreement, court, criminal procedure legislation, civil procedure legislation, reconciliation. 


\section{INTRODUCTION}

The criminal procedure legislation has been systematically modified since the beginning of the implementation of the concept of judicial reform. The humanization of justice, the deprivation of justice of an exclusively accusatory orientation is clearly traced in the introduction of conciliation and conciliation procedures into the criminal process. The conventional component, the contract must be considered an integral part of it.

The question of the use of terms inherent in another branch of law has been repeatedly raised in the literature. Can this phenomenon be called convergence? Quite. Moreover, it is worth agreeing that the convergence process is able to find solutions to such problems as an increase in the crime rate, the complexity of procedural activities, the protection of the rights of victims and their restoration (Okhlopkova, 2017). And, what is important, in the future - optimization of the burden on judicial and law enforcement agencies.

In the world practice, an agreement, a contract are not new categories. We dare to assume that they are an exception from the general criminal procedure order. At the same time, the apparent simplicity does not allow practitioners and process scholars to describe them as an elementary alternative to judicial proceedings, giving them a sub-constitutional character.

As practice shows, the desire to resolve the situation with negative consequences in both criminal and civil (as well as arbitration, administrative) proceedings is due to the appearance of the categories "dispute", "conflict".

The first thing to pay attention to is the nature of such a conflict. Next - the composition of the participants. Third, there are options for resolving the dispute, and fourth, this is the result itself and its form. The starting point will be the emergence of an initiative to resolve the dispute on the basis of concessions and conditions. In this case, the unifying factor is precisely reconciliation in the criminal procedural sense on the basis of the agreement reached. The use of this term has its roots in Roman law. As we can see, at present it is considered much broader and goes beyond property, civil relations.

It is impossible not to agree that its value lies in maintaining the normal functioning of public relations, maintaining their balance. Reconciliation is not only a process, but a set of consistent actions of the participants (Machuchina, 2018). It should not be forgotten that the criminal procedure sphere has a special range of application, unlike other branches. This is largely due to the provision of public interests, the entry into the arena of special subjects with discretionary powers.

\subsection{REVIEW AND ANALYSIS OF DOCUMENTS}

The agreement is a civil law institution, but it is thanks to its existence that conciliation and conciliation procedures have arisen in criminal proceedings. However, in our opinion, the admission of guilt (plea bargain) is underestimated by the legislator. One of the reasons for this conclusion is the lack of close attention to the subjective attitude of the perpetrator to what he did. During the implementation of most conciliatory and conciliatory forms, participants in the criminal process leave this category aside, which allows them to be compared with such a civil legal category as a settlement agreement on mutually beneficial concessions, in which the benefits side plays a dominant role. For example, art. 25 of the Criminal Procedure Code of the Russian Federation (art. 76 of the Criminal Code of the Russian Federation) contains an indication of reconciliation with the victim and making amends for harm. To make a decision on the termination of criminal proceedings in connection with active repentance (art. 28 of the Code of Criminal Procedure of the Russian Federation, art. 75 of the Criminal Code of the Russian Federation) it is not enough to admit guilt, it must be confirmed by the fulfillment of conditions and actions that indicate its true nature. The imposition of a fine under art. 25.1 of the Criminal Procedure Code of the Russian Federation is also possible when performing compensatory actions. After analyzing the norms of the Criminal Code and the Criminal Procedure Code of the Russian Federation, we come to the conclusion that practically no conciliatory or conciliatory criminal procedure requires a suspect (accused, defendant) to admit guilt as a basis, except for an inquiry in an abbreviated form. Thus, confessions are an additional bonus in the final decision.

In connection with the above, it is worth agreeing with the opinion that reconciliation should not be expressed in a rash acceptance of concessions (Chernyshova, 2012). The functions of reconciliation will be the restoration of the violated rights of the victim, which is inextricably linked with the awareness, acceptance and understanding of the guilty person of his act and the opportunity to correct the consequences. In addition, this factor will meet the goals of fair criminal proceedings. 
If we proceed from the classification of forms of historical development of conflict resolution proposed by Davydenko D. L., then the opinion that reconciliation in criminal proceedings does not fully meet the criterion of voluntariness, since it is forced, seems justified. In particular, T. V. Chernyshova pointed to the action of the "whip method", which is based on the threat of sanctions in case of failure to reach an agreement (Chernyshova, 2012). Thus, such situation will contradict the legal compromises that the scientific community is striving for, where, in our opinion, preference should be given to the admission of guilt, rather than the receipt of benefits by the violator.

At the same time, no matter how contradictory the relations regulated by different branches are, they operate in the same spheres of life, but from different viewing angles. At the same time, the development of universal inter-branch concepts does not yet indicate the merger of these spheres, since the basis for their differentiation is due to specific social relations and the nature of their violation.

The dispositive principles of the branches of law, public and private interests are recognized as indisputable differences by the scientific community. At the same time, it is impossible not to agree with the opinion of Golovko L. V., according to which the above features do not have an absolute character (Golovko, 2017).

Since the admission of guilt is not universal and not axiomatic, but is subject to mandatory verification, it, in the conditions of current law enforcement, should not be the main criterion for differentiating criminal procedures. However, in our opinion, its determining influence on the final decision is not excluded.

Turning to the initial sphere of implementation of the concept of agreement, we will see that the emphasis is placed on the single-root word "peace". A bad peace is better than a good quarrel - it is this proverb that most clearly and fully reflects the essence of the institution, the main principles of which are voluntariness, equality, cooperation and, importantly, confidentiality.

So, in the Russian civil process, the main goal of the agreement is to reconcile the parties, to find a compromise. An interesting point, in contrast to the criminal process, is the possibility of a judicial initiative of such a procedure, given that it is possible to declare about it up to the execution of a judgment, not to mention other stages of civil proceedings. The accessibility of this institute impresses with its simplicity.

But, despite this difference, the application of this concept in the criminal procedure sphere becomes more obvious due to the emergence of simplified proceedings, since their action is possible only when an agreement is reached.

In particular, the special procedure for taking a decision when agreeing with the indictment, as well as when concluding a pre-trial cooperation agreement, conciliation and conciliation procedures - somehow intersect with a plea bargain or an indictment. It is impossible to deny the absence of a complete coincidence in these terms, since agreeing with the accusation does not mean admitting guilt. However, if all the conditions are met, the defense party has the right to apply to the accused the provisions of the Criminal Code of the Russian Federation on the imposition of a more lenient sentence, even when considering the case in a general manner.

Speaking, for example, about the plea bargain as an institution of American criminal justice, there is no doubt about its confidentiality. Practice has shown that agreements of this kind have long gone beyond the courtrooms. In addition, it is initially based on confessions. With regard to Russian domestic criminal process, not everything is so clear. On the one hand, the subject composition, the procedure for submitting a petition by the accused, makes the procedure itself transparent. The court performs its direct function only after the receipt of the case materials. This fact indicates indirect judicial control, as a result of which the case may be considered and not in accordance with section 10 of the Code of Criminal Procedure of the Russian Federation. On the other hand, the conclusion of a cooperation agreement occurs only at the stage of preliminary investigation. Is attention paid to confessions? There is no remorse, only a statement of the facts of the acts committed, including by accomplices.

Since the world legal community, taking into account the recommendations and standards of international organizations, is increasingly characterized by a tendency to soften legal norms, simplify legal procedures, there is an adjustment of national legislation by countries belonging to both the American model and the continental one.

In particular, the influence of westernism was reflected in the Criminal Procedure Code of Kazakhstan, which provided not only an accelerated pre-trial investigation, but also agreements in the form of a plea bargain both at the pre - trial and judicial stages, as well as an innovation - reconciliation as a result of the mediation process. We believe that the legislator includes in the meaning of the plea bargain exactly agreement with the volume of evidence and the amount of damage caused. Thus, he avoids pointing out the very fact of 
guilt. At the same time, the norms on reconciliation and active repentance retain the influence of Russian legislation.

Analyzing the norms of Germany, we come to the conclusion about the cautious attitude of lawmakers to the institution of a plea bargain. In its pure form, it is absent, which is obvious, since such transactions in Germany are characterized by great resistance with the right to fair punishment, not to mention the essence of the adversarial (inquisitorial) process. However, according to the German Criminal Procedure Code, the subject of agreements can be the legal consequences of the final decision, specific actions of the participants, but not the guilty verdict itself or corrective measures. Their basis should be the admission by the accused, and the position of the court is crucial. When termination of the proceedings, the admission of guilt is not mandatory, it is important to perform restorative and compensatory actions. In the course of accelerated or summary (simplified) procedure, the correctness of the established factual circumstances is of great importance.

If we return to the basic principles, then, both in criminal and civil proceedings, special attention is paid to the voluntary nature of the decision taken by the party.

We agree with the opinion that this feature suffers most when admitting guilt, since there are no full-fledged procedural guarantees. In particular, the admission of guilt is replaced by the possibility of self-incrimination or voluntary delusion (Perekrestov. 2013). Practitioners and scientists are tasked with eliminating these "vices".

Thus, the probability of establishing facts indicating a violation of the guidelines passes into the status of mandatory cancellation of the conciliation (in civil proceedings as well) procedure.

Another important distinguishing aspect is the result of the agreement. In particular, in criminal proceedings a sentence with procedural consequences in the form of a prescribed punishment for the convicted person or options for terminating the case (for example, reconciliation of the parties, active repentance).

\section{CONCLUSION}

Summing up the above, we come to the conclusion that the nature of the "settlement agreement" is manifested in the course of the implementation of criminal procedural activities in a transformed form. Of course, the term "settlement agreement" in its pure form is not found in the Criminal Procedure Code of the Russian Federation, but its signs are clearly visible both when a criminal case is terminated in connection with the reconciliation of the parties, and when considering a civil claim. We believe that the emphasis should be not only on discussing mutually beneficial conditions, but also on observing the guidelines of procedural activity, striving to establish all the circumstances of what was done, restoring the violated rights of victims, when establishing the guilt of the person involved, taking the necessary measures to correct it.

There is no denying that the issues of resolving tort conflicts through the use of conciliation procedures are currently gaining momentum. The term "mediation" is closely related to the settlement agreement, which in most cases is inherent in the civil branch of law. Many authors recognize its existence in criminal proceedings, noting the process of discussing mutually acceptable conditions for both parties. At the same time, ideally, the starting point should be an admission of guilt, and not just the fact of reaching an agreement (Apostolova, 2010). But, despite the fact that the discussion about the introduction of a mediator in the criminal process has been going on for a long time, the legislator is in no hurry to introduce this institution. We dare to assume that the reason for this may be a sufficient multi-personality of criminal procedural activity, where both a lawyer and a prosecutor may well perform the function of a "mediator", presenting a variant of the final solution of the issue to the court. Thus, the existence of an independent mediator, but with a special status, is not questioned.

Can the mediation potential be unlocked in the framework of criminal proceedings? We believe that we will not get an answer to this question in the near future. A likely development of the discussions may be the clarification and enhancement of conciliation procedures within the framework of the current criminal procedure legislation, the introduction of a "mediator" in the pre-procedural stage, when law enforcement resources are involved. In this case, "mediation" will meet the requirements imposed on it regarding reducing the workload, reducing the terms of punishment, resolving the conflict directly between the victim and the harmer in the criminal process. Will mediation pay more attention to the opinion of the victim? Undoubtedly.

This conclusion is also indicated by the recommendations of the Committee of Ministers of the Council of Europe No. R (99) 19 of 15.09.1999 concerning mediation in penal cases, and the standards of restorative mediation developed on their basis (approved by the All-Russian Association of Restorative Mediation 17.02.2009). 


\section{REFERENCE LIST}

Okhlopkova A. S. Features of unification of the norms of criminal procedure of the Russian Federation in the process of convergence of law / A. S. Okhlopkova // Eurasian Legal Journal. - 2017. - № 9(112). Pp. 265-268.

Machuchina O. A. Institute of Reconciliation: theoretical and legal foundations/Abstract of the thesis for the academic degree. Kaliningrad. 2018, p., 13

Chernyshova T. V. Reconciliation in law: the concept and types/Thesis for the degree of Candidate of Legal Sciences. Moscow, 2012, pp. 13-104

The course of criminal procedure / Ed. by iuris doctor, prof. L. V. Golovko. - 2nd ed., ispr. - M.: Statute, 2017., p. 285.

Perekrestov V. N. Improvement of the system of guarantees of voluntary admission of guilt//Vestnik of Volgograd state University. Ser. 5, Yurisprud. 2013. No. 2 (19), pp. 160-165

Apostolova N. N. Mediation (mediation) in criminal cases//Russian justice. - issue 3. - Moscow: Yurist, 2010. - pp. 55-58. 